${ }^{1}$ Department of Pedodontics, Orthodontics and Preventive Dentistry, College of Dentistry, University of Mosul, Mosul, Iraq

${ }^{2}$ Department of Pedodontics, Orthodontics and Preventive Dentistry, College of Dentistry, University of Mosul, Mosul, Iraq

${ }^{3}$ Department of Pedodontics, Orthodontics and Preventive Dentistry, College of Dentistry, University of Mosul, Mosul, Iraq.

Corresponding author:

Ali R. Al-Khatib

Department of Pedodontics, Orthodontics and Preventive Dentistry, College of Dentistry, University of Mosul, Mosul, Iraq Email: alirajih@uomosul.edu.iq

Received: January 24, 2020

Accepted: June 29, 2020

\section{The effect of different mouth washes and text messages reminder in the oral health of orthodontic patients}

\author{
Saba N. Yaseen ${ }^{1}$ (D, Aisha A. Qasim² (D), Ali R. Al-Khatib, ${ }^{3, *}$ (D)
}

Aim: The aim of this study was to investigate the effect of different mouth washes and to study the effect of text message reminder on the oral health status of orthodontic patients treated with fixed appliances. Methods: This study was a clinical trial with pre-test and post-test control group design, conducted on 24 patients undergoing fixed orthodontic treatment aged 15-30 years. The patients randomly divided into two groups; one received a weekly telephone text massage reminder for the instructions of brushing and rinsing while the second group did not receive any messages. Ortho-plaque index and gingival index were used to evaluate the patient's oral hygiene status. The reading indices after brushing only were regarded as a control, then the patients were instructed to use two mouth washes, one containing sodium fluoride with cetylpyridinium chloride, the second containing chlorhexidine digluconate with cetylpyridinium chloride and Aloe Vera. Each one was used routinely for 4 weeks with the same amount and method. The washout period between the two types mouth washes was 4 weeks with a standardized toothbrush and paste. Results: Ortho-plaque index values decreased over the time between first, second and third visits. However, this index raised up at the fourth visit and again dropdown at the fifth visit. Similar results were detected for gingival index. Also, significant interaction between messages and the assessments was recorded for gingival index with a significant difference between the group of text messages and without text messages group $(p<0.05)$. Conclusions: The results of this study showed that the combination of sodium fluoride with cetylpyridinium chloride was more potent for plaque control, while chlorhexidine digluconate with cetylpyridinium chloride and Aloe Vera combination showed a better gingival improvement. Moreover, the text messages reminder could enhance, but not replace direct oral hygiene instruction in orthodontic patients.

Keywords: Aloe Vera, Cetylpyridinium chloride, Chlorohexidine, Text Messages. 


\section{Introduction}

Malocclusion is considered as one of the important problems in dental health which is usually relieved by orthodontic treatment ${ }^{1}$. This procedure encourages the accumulation of dental plaque that increases the risk of dental caries and periodontal diseases ${ }^{2,3}$.

During orthodontic treatment, these problems can be controlled via maintaining effective oral hygiene. However, proper mechanical control is not performed effectively by the majority of the population, mainly due to the lack of the motivation and manual skill. Therefore, the use of chemical agents as an adjunct to mechanical tooth cleaning has been shown to be useful in plaque control for patients ${ }^{4}$.

Chemotherapeutic agents such as mouth washes and dentifrices can act as a clinical adjunct for reducing the dental health problems during the active phase of orthodontic treatment ${ }^{5,6}$. Among available products, chlorhexidine $(\mathrm{CHX})$ is highly effective in the reduction of dental plaque and gingivitis ${ }^{7,8}$. However, $\mathrm{CHX}$ mouth rinses have some drawbacks such as reversible discoloration of the teeth and tongue, desquamation of the oral mucosa, burning sensation and dryness of the mouth ${ }^{8}$.

Another product that usually recommended in dental practice is fluoridated mouth washes. Over years, fluoride plays a significant role as an anti-cariogenic product, due to its inhibitory action against salivary Streptococcus mutans. Sodium fluoride (NaF) rinses have been applied to reduce enamel decalcification, plaque formation and gingivitis ${ }^{9}$. Combinations with other products including $\mathrm{CHX}$ are now available for further improvement of oral health ${ }^{10}$.

Cetylpyridinium chloride (CPC) is an agent used to control formation of the plaque. Authors indicated that the regular use of CPC mouth washes reduced oral bacteria, controlled biofilms, and gingivitis ${ }^{11,12}$. In another study, Ghiraldini et al. ${ }^{13}$ examined the effects of $0.5 \%$ CPC in combination with $12.5 \%$ xylitol on the formation of dental plaque and gingivitis. This combination recorded a positive effect on dental biofilm, but have limited action against the gingivitis. In another clinical trial, mouth washes containing $0.1 \%$ CPC showed an effective in preventing plaque formation, however, no statistically significant effects recorded against gingivitis ${ }^{14}$.

Additionally, Aloe Vera is used as an effective anti-inflammatory and anti-microbial agent ${ }^{15,16}$. Vangipuram et al. ${ }^{17}$ compared the efficacy of Aloe Vera (99\% aloe juice) and $0.12 \% \mathrm{CHX}$ mouth washes for 30 days. They found no significant difference in plaque and gingival indices between the two types of mouth washes.

All previously mentioned chemical products represent a practical options in controlling oral hygiene. Their effect can be increased by the combination of other substances that can contribute further improvement of oral status. For example, Farid Ayad et al. ${ }^{18}$ showed that a mouth wash with $\mathrm{CPC}$ and NaF has a clinical superiority in reducing plaque and gingivitis in comparison to mouth wash containing only $\mathrm{NaF}$. Also, CPC and hyaluronic acid mouth wash was proven to be more effective against plaque and gingivitis compared with $0.20 \% \mathrm{CHX}$ rinse $^{19}$.

In addition to chemotherapeutic agents, it is very important to emphasize the oral hygiene instructions for orthodontic patients treated with a fixed appliance ${ }^{20}$. An earlier study showed that oral hygiene can be improved with the reward system or active 
reminder therapy ${ }^{21}$. Another study demonstrated the significant positive influence of text messages on behavioral changes ${ }^{22}$. Nowadays, mobile usage has increased dramatically, automated text messages even help to keep the dentist in contact with patients during longer appointment intervals. So, the text message reminder method is effective for improving the oral hygiene of patients during dental practice ${ }^{23,24}$.

Several types of mouth washes are available today, they may confuse both patient and dentist about the most useful and effective type to reduce or eliminate oral hygiene problems during orthodontic treatment.

According to the best of our knowledge, limited information is available regarding the comparative efficacy of ( $\mathrm{NaF}$ and $\mathrm{CPC}$ ) with ( $\mathrm{CHX}, \mathrm{CPC}$, and Aloe Vera) combinations on oral hygiene during orthodontic treatment. Moreover, no studies have tested the effect of reminder text messages on dental health throughout the period of orthodontic therapy. Thus, the aims of this study were to compare the effects of mouth wash that contains ( $\mathrm{NaF}$ and $\mathrm{CPC}$ ) with others that contain ( $\mathrm{CHX}, \mathrm{CPC}$ and Aloe Vera). Also, study the effect of the text messages reminder regarding oral hygiene on the oral health status of orthodontic patients. The null hypotheses tested are that:

1. There is no difference between mouth wash that contains ( $\mathrm{NaF}$ and $\mathrm{CPC}$ ) and that which contains ( $\mathrm{CHX}, \mathrm{CPC}$ and Aloe Vera) regarding anti-plaque and anti-gingivitis activities in orthodontic patients.

2. There is no effect of text messages reminder regarding oral hygiene on the oral health status of orthodontic patients.

\section{Materials and Methods}

The ethical approval No. 5033 was released by the academic authorities at University of Mosul in 2018.

\section{Trial design and sample size:}

This is a randomized, controlled, crossover clinical trial conducted between December 2018 and May 2019. The study conducted on a total of 24 patients underwent fixed orthodontic appliance treatment (16 females, 8 males) aged 15-30 years (mean age 18 years) randomly selected from a private practice clinic at Duhok City in the north of Iraq. The sample size was calculated on the basis of single mean formula $\left[n=(z r / D)^{2}\right]$. Resulted number was adjusted, and the final sample size was $=n+(n \times 0.2)$. In this study, $n$ was considered as the number of subjects, $z=1.96$ for $95 \%$ confidence, $r$ (standard deviation) $=0.32 .{ }^{25}$ and $(D)$ precision $=0.2$ unit accordingly, the estimated total sample size was 12 participants for each study group.

\section{Eligibility criteria and randomization procedures:}

The inclusion criteria were as follows:

1. No significant medical/dental problems.

2. No history of antibiotic consumption for at least three months before the study.

3. No dental hygienic intervention during a month preceding the study, including mouth washes utilization. 
4. No smoking.

5. No mouth breathing.

6. No known hypersensitivity to $\mathrm{CHX}$ and/ or any other mouth washes.

In the present study, aim and procedures were explained to subjects who agreed to participate in this study. Each eligible participant has received specific sequential number. Such a number was written on precise sheet which was placed in a container by randomly chosen researcher (SNY). Thereafter, another randomly chosen researcher (ARK) selected the participants for the study groups with an equal allocation ratio. All of study participants underwent fixed orthodontic therapy. The brackets used in this study were 0.022 stainless steel Mini Roth brackets of mesh (Ortho Technology Inc., Tampa, FL).

\section{Interventions:}

\section{Text messages:}

Each participant has his / her own cellular telephone with text messaging services. They were randomly divided into two equal groups; the first group received a weekly telephone text message reminder for the instructions of brushing and rinsing and the second group did not receive any messages.

Messages group received one text message each Friday morning during all the study period. The text message was: Hello, I hope that you are well. This is a reminder messages to follow the oral hygiene instructions given to you. Best regards.

\section{Assessments:}

Total time of assessments was four months. Assessment of Otho-plaque (OPI) and Gingival (GI) indices was done on each monthly visit of orthodontic patients by the same examiner. In order to exclude the individual variations between the patients regarding their oral environments and their commitments to the instructions, the two tested mouth washes were conducted by the same participant in the study period.

First assessment: This represents the (baseline assessment) that was taken before any interventions. At the beginning of the visit, (OPI) and (GI) indices were recorded for the participants. All, participants received free standardized toothpaste (OrthoKin Strawberry Mint toothpaste, Kin, Barcelona - Spain) and a soft orthodontic toothbrush (Kin, Barcelona - Spain). Oral hygiene instructions were given to the participants by the same examiner. Participants were instructed to brush their teeth three times daily after meals with a constant amount of tooth paste using a colored marker on the tooth brush with horizontal brushing technique for two minutes.

Second assessment: This is a positive control that represents the effect of brushing only without any mouth wash. After four weeks of the brushing, (OPI) and (GI) indices were recorded for the same participants in each group. At the end of the appointment, participants were given the first mouth wash (MW1) that contains 0.11 sodium fluoride, 0.05 cetylpyridinium chloride and 100ml excipients (OrthoKin Strawberry Mint mouth wash, Kin, Barcelona - Spain) with instructions of use twice a day for 
4 weeks period, (10 $\mathrm{ml}$ for one minute) after lunch and before bedtime. Subjects were instructed to avoid eating and drinking for 30 minutes after rinsing.

Third assessment: This represents the effects of (MW1). After four weeks of rinsing with (MW1), (OPI) and (GI) indices were recorded again for the same participants. Then, participants were instructed to use brushing only without any mouth wash. This step is considered as a washout period.

Fourth assessment: This represents the washout period where the participants use brushing only without any mouth wash. After four weeks of washing out, (OPI) and (GI) indices were recorded for the same participants. Then, they received the second mouth wash (MW2) that contains $0.05 \mathrm{CHX}$ digluconate, 0.05 cetylpyridinium chloride, 0.062 Aloe Vera and $100 \mathrm{ml}$ excipients (Kin Care mouth wash, Kin, Barcelona Spain) with the same instructions of the (MW1).

Fifth assessment: This represents the effects of (MW2). (OPI) and (GI) indices for all participants were recorded again after four weeks of (MW2) utilization.

Outcome: The main outcome of the study was ortho-plaque Index and Gingival Index for the two main groups of orthodontic patients (with text massage and without text massage) groups.

\section{Ortho-plaque index}

Evaluation of plaque was done using Ortho-plaque Index (OPI). It is a special index used for patients with fixed orthodontic appliances ${ }^{26}$. In this study, disclosing tablets (MGS Disclosing Tablets, GAP Research Co., UI) for the index calculation was used. The participant was asked to chew one tablet for 30 seconds, sluice saliva over the teeth and through the inter dental gaps, finally spit the tablet and saliva directly into a spittoon. Standardized digital images were taken to the participant's teeth from frontal, right and left and lateral views (Fig.1). The images were analyzed to measure the percentage of the area covered by plaque ${ }^{27}$.
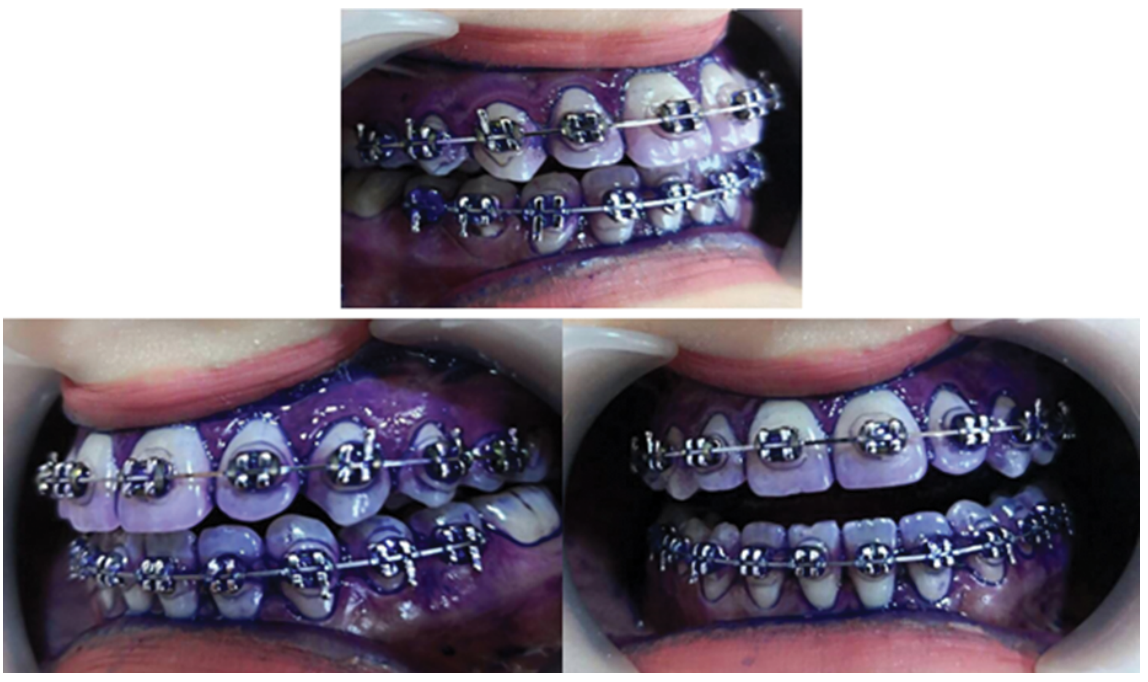

Figure 1. Coloured dental plague after application of disclosing tablet from frontal and lateral views 


\section{Photographic analysis}

Photographs were analyzed to measure the percentage of the area covered by plaque using digital image analysis of these photographs ${ }^{27}$. The advantages of a photograph are that they can be assessed at free time, they are permanent record, can be viewed on numerous occasions and enable reproducibility of assessment ${ }^{28}$. Yes-No system was used in the evaluation of the dyed plaque in three areas of the buccal surface of the tooth. Depending on the accessibility for cleaning, each area has its own level of difficulty (Fig. 2).

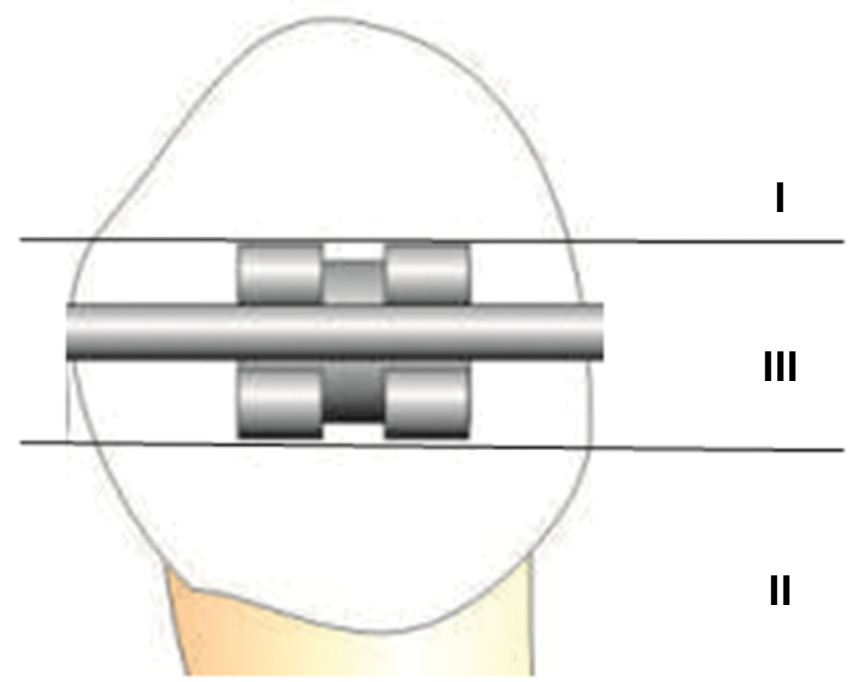

I = occlusal area (easily accessible) = score 1

II = cervical area (accessible with certain difficulty) = score 2

III = central area (poorly accessible) $=$ score 3

Figure 2. Scheme distribution of the buccal surface of a tooth for evaluation of OPI according to Ticha et al. ${ }^{29}$

I = occlusal area (easily accessible) = score 1,

II = cervical area (accessible with certain difficulty) = score 2 ,

III = central area (poorly accessible) $=$ score 3 .

Values found were entered into a work table (Tab. 1). The following formula was used in calculating $\mathrm{OPI}^{29}$.

OPI \% = (Total value from dyed areas / Total number of teeth $\times 6) 100 \%$

The condition of oral hygiene was evaluated according to the following scheme ${ }^{29}$.

0-30\%= excellent hygiene,

30-50\%= average hygiene,

over $50 \%$ = insufficient hygiene. 
Table 1. Orthodontic Plaque Index: recorded dental plaque in individual areas multiplied by the relevant factor of cleaning difficulty ${ }^{29}$

\begin{tabular}{|c|c|c|c|c|c|c|c|c|c|c|c|c|}
\hline Cervical & $\mathrm{X} 2$ & & & & & & & & & & & Total \\
\hline Central & X3 & & & & & & & & & & & Total \\
\hline Occlusal & $\mathrm{X} 1$ & & & & & & & & & & & Total \\
\hline Teeth & & 5 & 4 & 3 & 2 & 1 & 1 & 2 & 3 & 4 & 5 & \\
\hline Occlusal & $\mathrm{X} 1$ & & & & & & & & & & & Total \\
\hline Central & X3 & & & & & & & & & & & Total \\
\hline Cervical & $\mathrm{X} 2$ & & & & & & & & & & & Total \\
\hline
\end{tabular}

\section{Gingival Index}

Loe and Silness's Gingival Index (GI) was used to measure the gingival status ${ }^{30}$. The scored teeth:16,12,24,36,32 and 44. Each of four surfaces of the tooth near the gingival margin was scored according to the following criteria:

$0=$ Normal gingiva (absence of inflammation),

1 = Mild inflammation (slight alteration in color, slight edema, no bleeding on probing),

2 = Moderate inflammation (moderate glazing, edema, redness, hypertrophy and bleeding on probing),

3 = Sever inflammation (obvious redness, hypertrophy, ulceration, and tendency to spontaneous bleeding).

\section{Statistical Analyses:}

In this study, the descriptive statistics including mean and standard deviation were used to present the data. Whereas, The two way repeated measures ANOVA was recorded to assess the difference between and within the study groups for OPI and $\mathrm{GI}$. The significance level was sited at $p<0.05$.

\section{Calibration Procedures:}

Before data collection, the calibration and intra-examiner reliability were assessed, an examinations of 10 subjects were conducted on two occasions by the same examiner (SNY) using the study indices (OPI and GI). Intra-examiner reliability was tested using intra-class correlation ( $0.91 \%$ and $0.93 \%$ ) for OPI and GI respectively.

\section{Results}

In this study, 36 orthodontic patients with fixed appliances were examined, 12 subjects were excluded because 10 of them did not meet the inclusion criteria and 2 subjects refused to participate. Twenty four orthodontic patients were included and distributed equally in the study groups as shown in the flow chart (Fig. 3). Descriptive statistics including mean values and standard deviations were determined for each index (Tab. 2). The OPI values showed a decrease over time among first, second and 


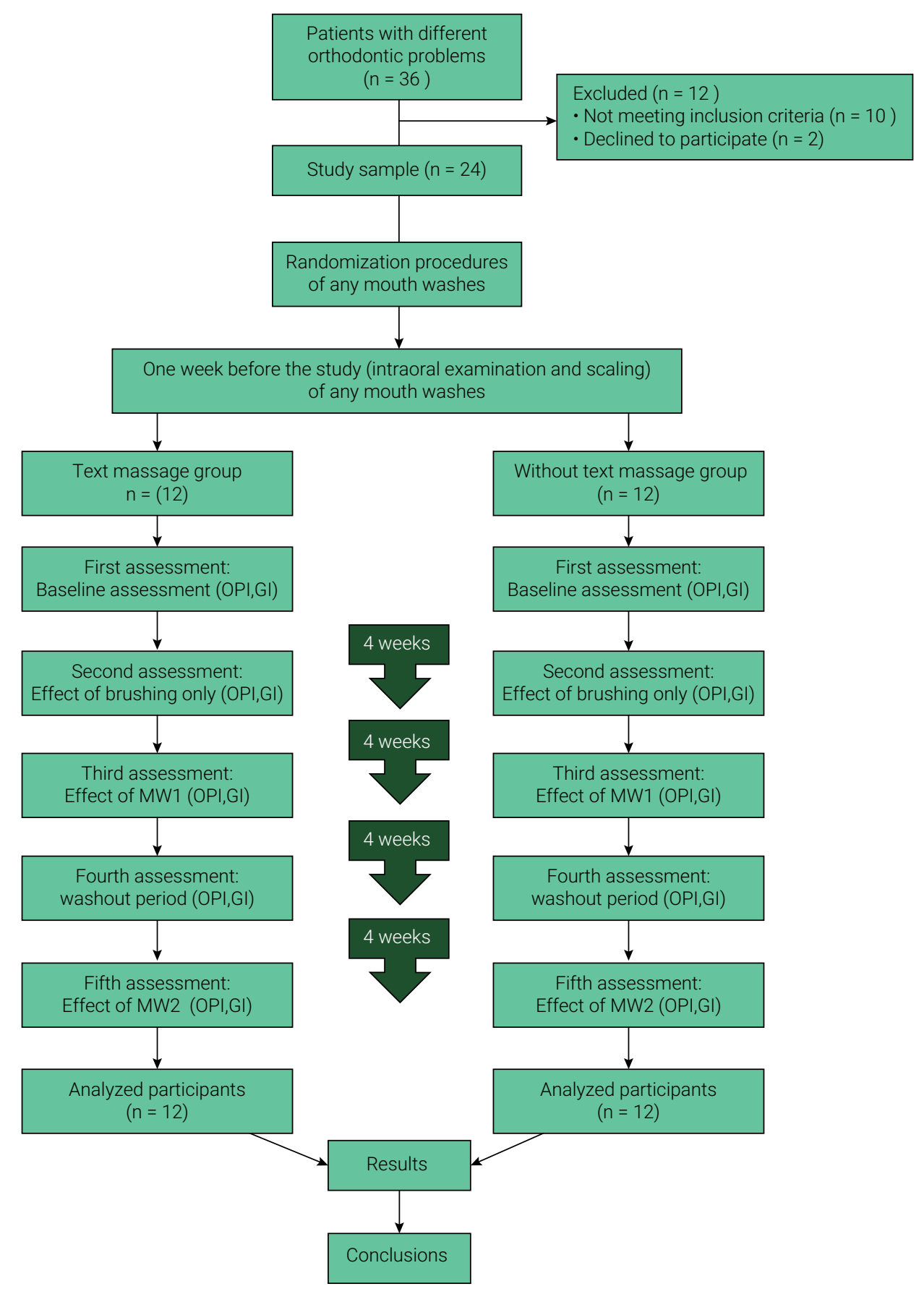

Figure 3. diagrammatic illustration for the study flow chart

third readings. However, this index raised up at the fourth visit and again dropdown at the fifth visit and similar values were recorded for GI (Figs. 4 and 5). Also, higher mean values of $\mathrm{OPI}$ and $\mathrm{Gl}$ in with text messages group were recorded alone the study groups (Tab. 2). 


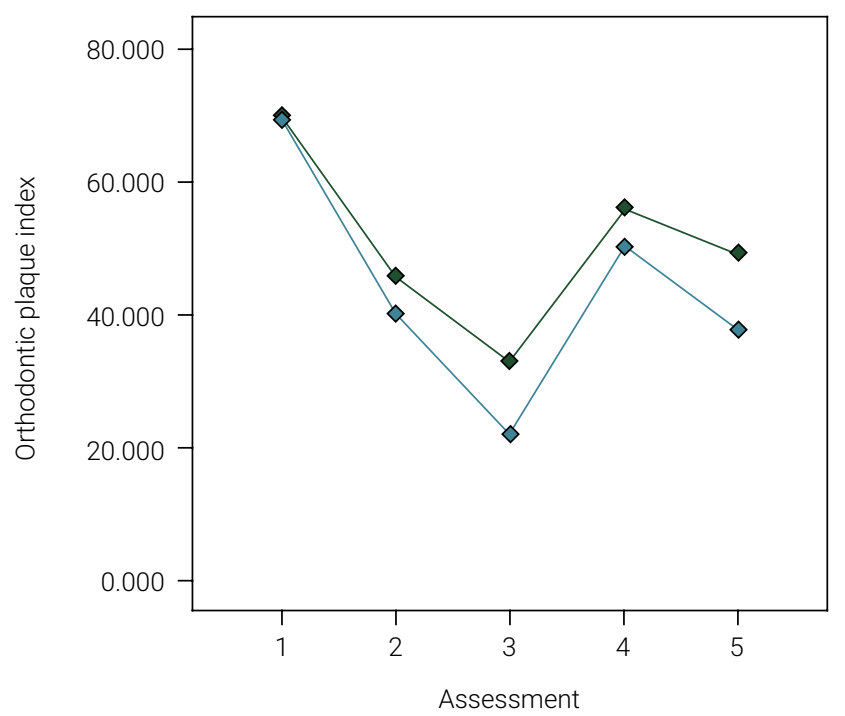

Without text message

With text message

Figure 4. Shows the means plot of Ortho-plaque index change (total values) throughout study period

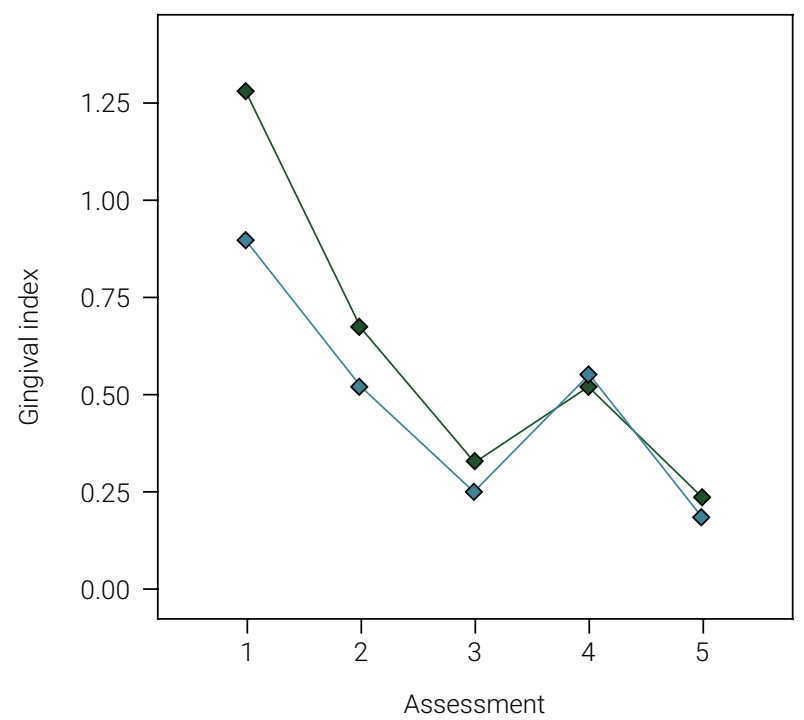

Without text message

With text message

Figure 5. Shows the means plot of gingival index change (total values) throughout study period

Table 2. Mean values and standard deviations (SD) for study indices at each visit according to the text messages groups

\begin{tabular}{lccccc}
\hline \multirow{2}{*}{ Assessments } & \multirow{2}{*}{ Groups } & \multicolumn{2}{c}{ OPI } & \multicolumn{2}{c}{ GI } \\
\cline { 2 - 6 } & & Mean & SD & Mean & SD \\
\hline \multirow{2}{*}{\begin{tabular}{l}
$1^{\text {st }} \begin{array}{l}\text { (bassessment } \\
\text { (baseline) }\end{array}$ \\
\cline { 2 - 6 }
\end{tabular}} & without text message $(n=12)$ & 69.33 & 20.96 & 0.90 & 0.49 \\
\cline { 2 - 6 } & with text message $(n=12)$ & 70.27 & 13.47 & 1.28 & 0.20 \\
\hline & Total $(n=24)$ & 69.80 & 17.24 & 1.09 & 0.41 \\
\hline
\end{tabular}


...continuation.

\begin{tabular}{|c|c|c|c|c|c|}
\hline \multirow{2}{*}{ Assessments } & \multirow{2}{*}{ Groups } & \multicolumn{2}{|c|}{ OPI } & \multicolumn{2}{|c|}{ GI } \\
\hline & & Mean & SD & Mean & SD \\
\hline \multirow{3}{*}{$\begin{array}{l}2^{\text {nd }} \text { assessment } \\
\text { (brushing only) }\end{array}$} & without text message $(n=12)$ & 40.21 & 21.28 & 0.52 & 0.17 \\
\hline & with text message $(n=12)$ & 45.75 & 16.73 & 0.67 & 0.17 \\
\hline & Total $(n=24)$ & 42.98 & 18.93 & 0.59 & 0.18 \\
\hline \multirow{3}{*}{$\begin{array}{l}3^{\text {rd }} \text { assessment } \\
(\mathrm{MW} 1)\end{array}$} & without text message $(n=12)$ & 21.95 & 17.44 & 0.25 & 0.17 \\
\hline & with text message $(n=12)$ & 33.01 & 15.42 & 0.33 & 0.11 \\
\hline & Total $(n=24)$ & 27.48 & 17.06 & 0.29 & 0.14 \\
\hline \multirow{3}{*}{$\begin{array}{l}4^{\text {th }} \text { assessment } \\
\text { (washout) }\end{array}$} & without text massage $(n=12)$ & 50.25 & 13.27 & 0.55 & 0.25 \\
\hline & with text massage $(n=12)$ & 56.01 & 16.62 & 0.52 & 0.25 \\
\hline & Total $(n=24)$ & 53.12 & 15.01 & 0.54 & 0.25 \\
\hline \multirow{3}{*}{$\begin{array}{l}5^{\text {th }} \text { assessment } \\
\text { (MW2) }\end{array}$} & without text massage $(n=12)$ & 37.72 & 14.83 & 0.18 & 0.08 \\
\hline & with text massage $(n=12)$ & 49.27 & 14.09 & 0.24 & 0.14 \\
\hline & Total $(n=24)$ & 43.50 & 15.33 & 0.21 & 0.12 \\
\hline
\end{tabular}

Orthodontic plaque index (OPI), Gingival index (GI), Mouth wash 1 (MW1), Mouth wash 2 (MW2)

\section{Analysis of variance}

The two way repeated measures ANOVA were recorded for the OPI and GI.

\section{Ortho-plaque index}

The results of OPI showed that there was no significant interaction between messages and the assessments ( $F$ value $=0.85, p$ value $=0.434)$. Also, results showed that there were no significant differences between the group of with text messages and without text messages group $(F$ value $=1.83, p$ value $=0.203)$. Significant main effect for the assessments was recorded ( $F$ value $=40.76, p$ value $=0.001)$, since it has 5 levels, post hoc test was conducted (Tab. 3). In terms of Scheffe's post Hoc test, the difference in OPI between $4^{\text {th }}$ and $5^{\text {th }}$ visits was significantly smaller than in the other comparisons $(p<0.05)$ (Tab. 3). However, the OPI in $2^{\text {nd }}$ visit did not differ significantly when compared to the $4^{\text {th }}$ and $5^{\text {th }}$ visits.

Table 3. Post Hoc Scheffe's pairwise comparisons within study groups for OPI

\begin{tabular}{lll}
\hline Comparison & \multicolumn{1}{c}{ Mean difference of OPI } \\
\hline & $2^{\text {nd }}$ & $26.81^{*}$ \\
\cline { 2 - 3 } $\begin{array}{l}1^{\text {st }} \text { assessment } \\
\text { (baseline) }\end{array}$ & $3^{\text {rd }}$ & $42.32^{*}$ \\
\cline { 2 - 3 } & $4^{\text {th }}$ & $16.67^{*}$ \\
\hline \multirow{2}{*}{$\begin{array}{l}2^{\text {nd }} \text { assessment } \\
\text { (brushing) }\end{array}$} & $5^{\text {th }}$ & $26.30^{*}$ \\
\cline { 2 - 3 } & $1^{\text {st }}$ & $26.81^{*}$ \\
\cline { 2 - 3 } & $3^{\text {rd }}$ & $15.50^{*}$ \\
\hline
\end{tabular}


...continuation.

\begin{tabular}{|c|c|c|}
\hline Comparison & & lifference of OPI \\
\hline \multirow{4}{*}{$\begin{array}{l}3^{\text {rd }} \text { assessment } \\
\text { (MW1) }\end{array}$} & $1^{\text {st }}$ & $42.32^{*}$ \\
\hline & $2^{\text {nd }}$ & $15.50^{*}$ \\
\hline & $4^{\text {th }}$ & $25.64^{*}$ \\
\hline & $5^{\text {th }}$ & $16.01^{*}$ \\
\hline \multirow{4}{*}{$\begin{array}{l}4^{\text {th }} \text { assessment } \\
\text { (washout) }\end{array}$} & $1^{\text {st }}$ & $16.67^{\star}$ \\
\hline & $2^{\text {nd }}$ & 10.14 \\
\hline & $3^{\text {rd }}$ & $25.64^{*}$ \\
\hline & $5^{\text {th }}$ & $9.62^{*}$ \\
\hline \multirow{4}{*}{$\begin{array}{l}5^{\text {th }} \text { assessment } \\
\text { (MW2) }\end{array}$} & $1^{\text {st }}$ & $26.30^{*}$ \\
\hline & $2^{\text {nd }}$ & 0.51 \\
\hline & $3^{\text {rd }}$ & $16.01^{*}$ \\
\hline & $4^{\text {th }}$ & $9.62^{*}$ \\
\hline
\end{tabular}

*Significant at $p<0.05$

Orthodontic plaque index (OPI), Mouth wash 1 (MW1), Mouth wash 2 (MW2)

\section{Gingival index}

The results of $\mathrm{Gl}$ showed that there were significant differences between the group of with text messages and without text messages group ( $F$ value $=6.60$, $p$ value $=0.026)$. Significant main effect for the assessments was recorded $(F$ value $=13.65, p$ value $=0.001)$. The repeated measures analysis of variance for $\mathrm{GI}$ showed that there was significant interaction between messages and assessments $(F$ value $=88.85, p$ value $=0.001)$. For that reason, the main effect was ignored and the simple main effects were examined. The difference in assessments within each study group was presented separately. The results for Scheffe's post Hoc test recorded significant difference in $\mathrm{Gl}$ values among the different study groups for both text and without text messages groups (Tab. 4).

\section{Discussion}

Orthodontic treatment by fixed appliances may extend for a considerable period of time producing difficult conditions for maintaining oral hygiene. For that reason, patients must gain a full understanding of their responsibilities during this period and have to be involved in preventive programs to maintain proper oral hygiene. In this study, the clinical effect of two different mouth washes in addition to the motivation by text messages were assessed. The results of this study showed that the mouth wash with ( $\mathrm{NaF}$ and $\mathrm{CPC}$ ) was more potent for plaque control, while mouth wash with $(\mathrm{CHX}+\mathrm{CPC}$ and Aloe Vera combination) showed better gingival improvement. So, the null hypothesis of the first objective was rejected.

Moreover, the result of the current study showed significant difference between text message and without text message groups regarding GI only. This indicate that the text messages reminder could enhance, but not replace direct oral hygiene instruction in orthodontic patients ${ }^{31}$. So, the null hypothesis of the second objective was also rejected. 
Table 4. Post Hoc Scheffe's pairwise comparisons within each study groups for GI

\begin{tabular}{|c|c|c|c|}
\hline Group & & Comparison & Mean difference of GI \\
\hline \multirow{20}{*}{ Without text massage } & \multirow{4}{*}{$\begin{array}{l}1^{\text {st }} \text { assessment } \\
\text { (baseline) }\end{array}$} & $2^{\text {nd }}$ & $0.38^{*}$ \\
\hline & & $3^{\text {rd }}$ & $0.64^{*}$ \\
\hline & & $4^{\text {th }}$ & $0.34^{*}$ \\
\hline & & $5^{\text {th }}$ & $0.71 *$ \\
\hline & \multirow{4}{*}{$\begin{array}{l}2^{\text {nd }} \text { assessment } \\
\text { (brushing) }\end{array}$} & $1^{\text {st }}$ & $0.38^{*}$ \\
\hline & & $3^{\text {rd }}$ & $0.26^{\star}$ \\
\hline & & $4^{\text {th }}$ & 0.03 \\
\hline & & $5^{\text {th }}$ & $0.33^{*}$ \\
\hline & \multirow{4}{*}{$\begin{array}{l}3^{\text {rd }} \text { assessment } \\
\text { (MW1) }\end{array}$} & $1^{\text {st }}$ & $0.64 *$ \\
\hline & & $2^{\text {nd }}$ & $0.26^{*}$ \\
\hline & & $4^{\text {th }}$ & $0.30 *$ \\
\hline & & $5^{\text {th }}$ & 0.07 \\
\hline & \multirow{4}{*}{$\begin{array}{l}4^{\text {th }} \text { assessment } \\
\text { (washout) }\end{array}$} & $1^{\text {st }}$ & $0.34^{*}$ \\
\hline & & $2^{\text {nd }}$ & 0.03 \\
\hline & & $3^{\text {rd }}$ & $0.30 *$ \\
\hline & & $5^{\text {th }}$ & $0.37 *$ \\
\hline & \multirow{4}{*}{$\begin{array}{l}5^{\text {th }} \text { assessment } \\
\text { (MW2) }\end{array}$} & $1^{\text {st }}$ & $0.71 *$ \\
\hline & & $2^{\text {nd }}$ & $0.33^{*}$ \\
\hline & & $3^{\text {rd }}$ & 0.07 \\
\hline & & $4^{\text {th }}$ & $0.37 *$ \\
\hline \multirow{20}{*}{ With text massage } & \multirow{4}{*}{$\begin{array}{l}1^{\text {st }} \text { assessment } \\
\text { (baseline) }\end{array}$} & $2^{\text {nd }}$ & $0.60 *$ \\
\hline & & $3^{\text {rd }}$ & $0.95^{\star}$ \\
\hline & & $4^{\text {th }}$ & $0.75^{\star}$ \\
\hline & & $5^{\text {th }}$ & $1.04^{\star}$ \\
\hline & \multirow{4}{*}{$\begin{array}{l}2^{\text {nd }} \text { assessment } \\
\text { (brushing) }\end{array}$} & $1^{\text {st }}$ & $0.60 *$ \\
\hline & & $3^{\text {rd }}$ & $0.34^{*}$ \\
\hline & & $4^{\text {th }}$ & 0.15 \\
\hline & & $5^{\text {th }}$ & $0.43^{*}$ \\
\hline & \multirow{4}{*}{$\begin{array}{l}3^{\text {rd }} \text { assessment } \\
\text { (MW1) }\end{array}$} & $1^{\text {st }}$ & $0.95^{\star}$ \\
\hline & & $2^{\text {nd }}$ & $0.34^{*}$ \\
\hline & & $4^{\text {th }}$ & 0.19 \\
\hline & & $5^{\text {th }}$ & 0.09 \\
\hline & \multirow{4}{*}{$\begin{array}{l}4^{\text {th }} \text { assessment } \\
\text { (washout) }\end{array}$} & $1^{\text {st }}$ & $0.75^{\star}$ \\
\hline & & $2^{\text {nd }}$ & 0.15 \\
\hline & & $3^{\text {rd }}$ & 0.19 \\
\hline & & $5^{\text {th }}$ & $0.28 *$ \\
\hline & \multirow{4}{*}{$\stackrel{5^{\text {th }}}{\text { assessment(MW2) }}$} & $1^{\text {st }}$ & $1.04^{\star}$ \\
\hline & & $2^{\text {nd }}$ & $0.43^{*}$ \\
\hline & & $3^{\text {rd }}$ & 0.09 \\
\hline & & $4^{\text {th }}$ & $0.28^{*}$ \\
\hline
\end{tabular}


Text messages can reduce plaque and gingival inflammation by reminding the patients at home to follow the instructions that were given to them at the clinic. While patients without text messages also could get a reduction in plaque index because they were already follow the instructions of brushing and rinsing that were given to them at the clinic, but may be in a less extend compared to text messages group. These patients might still have some plaque accumulation on their teeth that can lead to gingival inflammation. OPI used in this study gave a percentage of plaque accumulation with ranging, for example: 0 - 30\%= excellent hygiene but, there is difference between $0 \%$ plaque accumulation compared to $30 \%$ although they have the same score and this may be added to the limitations of using this index.

Previous studies found significantly lower scores for plaque, bleeding, and gingival indices in the text message group compared with control. They concluded that the text message reminder method is effective for improving oral hygiene and in maintaining communication with orthodontic patients ${ }^{23,24}$. Kumar et al. ${ }^{31}$ stated that text message reminder helps in the improvement of oral hygiene of patients under orthodontic treatment this approach is economical, useful for mass communication, and not disturbing to the patient's working conditions. Whereas, Li et al. ${ }^{32}$ found no difference in $\mathrm{PI}$ and modified gingivitis index between the two study groups in the pre and post-orthodontic treatment. However, they recorded that messaging helps in patient's management and education.

The diagnostic indices used in this study were OPI and GI. Orthodontic plaque index is a special index used for patients with fixed orthodontic appliances ${ }^{26}$. It has a higher diagnosis performance and accuracy compared to Quigley and Hein Index, and Modified Navy Plaque Index. Re-measurement of the stored images can be done for reliability and for comparability between studies ${ }^{27}$. But this index has not have been used widely by many authors, possibly because of its relative complexity of calculation when compared with the modified Silness and Lo"e index.

The outcome of our study recorded a significant reduction in OPI and $\mathrm{GI}$ among the $1^{\text {st }}$ (baseline), $2^{\text {nd }}$ (brushing only) and $3^{\text {rd }}(\mathrm{NaF}$ and PCP). The reduction in the OPI and GI between the $1^{\text {st }}$ and $2^{\text {nd }}$ assessment may be attributed patients' following the instructions given to them especially when they knew that they are part of the study. They are also given dental brush and toothpaste, this may encourage them to maintain their oral health. This is in agreement with Wang et al. ${ }^{33}$ who concluded that oral hygiene instructions can lead to the efficient control of dental plaque accumulation in patients with fixed orthodontic appliances.

The difference between the $2^{\text {nd }}$ and $3^{\text {rd }}$ assessments may be due to the use of mouth wash with brushing compared with the use of brushing only. This is in agreement with Pahwa et al. ${ }^{34}$ who concluded that cetylpyridinium mouth wash was found to be effective in reducing the bleeding and plaque index scores in orthodontic patients compared to the patients using brushing only. In contract to that, Wiraja et al. ${ }^{35}$ have shown that plaque control by mechanical means is always the most influential way in reducing plaque on fixed orthodontic patients while mouth wash has just a chemical assistance of reducing dental plaque. 
In our study, the OPI and GI index values raised up at the $4^{\text {th }}$ assessment and again dropdown at the $5^{\text {th }}$ assessment after rinsing with ( $\mathrm{CHX}, \mathrm{CPC}$, and Aloe Vera) combination. The raising up in the $4^{\text {th }}$ assessment may be due to that this visit represents the washout period (between the two types of mouth washes) when the patients used brushing only without any mouth wash. These results are in agreement with other studies that concluded that tooth brushing alone is not enough in maintaining oral hygiene of orthodontic patients, they suggested that prescribing of mouth washes is necessary to maintain a good oral hygiene ${ }^{34,36}$.

Regarding the second mouth wash (CHX, CPC and Aloe Vera), a dropdown of OPI and GI index values were recorded at the fifth visit. This result was in agreement with previous studies ${ }^{17,37,38}$. Also, these results were in accordance with Karim et al ${ }^{39}$ who found a significant reduction in plaque and gingival bleeding scores after using Aloe Vera mouth washes. Dehghani et al. ${ }^{40}$ concluded that the patients who instructed to maintain regular oral hygiene, in addition to mouth rinsing with $\mathrm{CHX}$ combined with other products can help in control plaque, decrease gingival inflammation and improve patients' oral health status.

Comparing the results of first and second mouth washes showed that the reduction in OPI was higher for (NaF and CPC), whereas GI reduction was higher for the (CHX, CPC and Aloe Vera combination). This indicated that (NaF and CPC) are more beneficial for plaque control. This may be attributed to fluoride that has the ability to reduce supragingival plaque by accumulation in the plaque and decreasing the proportion of Streptococcus mutans ${ }^{9}$. The results of this study were in agreement with Wiraja et al. ${ }^{35}$ who compared the effects of $0.05 \%$ sodium fluoride and $0.2 \% \mathrm{CHX}$ mouth washes on plaque index in orthodontic patients. They concluded that $\mathrm{NaF}$ mouth rinse significantly reduced plaque index compared to $\mathrm{CHX}$. However, they mentioned that the most effective way of reducing plaque is tooth brushing while mouth wash is just an additional way. Chauhan et al. ${ }^{36}$ indicated that among the mouth washes, fluoridated mouth wash seems to be more effective as compared to the mouth wash containing CPC. In another study, an attempt has been made to distinguish between $\mathrm{CHX}(0.06 \%), \mathrm{NaF}(0.05 \%)$ mouth washes and combined one with $\mathrm{CHX}-\mathrm{NaF}$. Although, no significant difference was recorded between groups, CHX-NaF demonstrated a higher decrease in bleeding, modified gingival and plaque indices ${ }^{40}$.

The results of this study indicated that the second mouth wash (CHX, CPC and Aloe Vera) was better for gingival improvement. The reduction in GI scores can be attributed to Aloe Vera component of this mouth wash. Aloe Vera extracts can reduce gingival inflammation by inhibition of the cyclooxygenase pathway and decrease prostaglandin synthesis from arachidonic acid. Some of the components of Aloe Vera like hyaluronic acid, Vitamin C and dermatan sulfate are involved in collagen synthesis, increasing the concentration of oxygen at the wound site due to the dilation of blood vessels and therefore, provide relief in swelling and bleeding gums ${ }^{39,41}$.

Furthermore, (CHX, CPC and Aloe Vera ) mouth wash contains $\mathrm{CHX}$ that is considered as the "Gold Standard" due to its broad anti-microbial spectrum. It is efficient against Streptococcus.mutans and Lactobacillus bacteria7,40. It can reduce gingival disease because of its anti-bacterial action against oral pathogens by increasing in cellular membrane permeability followed by the coagulation of cytoplasmic macromolecules ${ }^{7}$. So, it is advisable to use this mouth wash when orthodontic patients have 
gingival inflammation to get the benefits of it on gingiva and reduce the side effects of prolong use of $\mathrm{CHX}$ at the same time.

Finally, CPC (which present in both mouth washes) had significant anti-plaque and anti-gingival effect and revealed a wide spectrum of anti-microbial activity ${ }^{12,37}$. CPC is a cationic surface-active agent that can rapidly kills gram-positive pathogens and yeasts by disrupting the membrane function, cell membrane damage causing leakage of cell components and finally cell death ${ }^{42}$.

The main limitations of this study were:

1. No negative control availability, because it is difficult to instruct the orthodontic patients to avoid tooth brushing.

2. There may be an individual variations between the participants regarding their response to the instructions.

The results of this study showed that:

1. The incorporation of mouth wash with standard tooth brushing procedures can significantly improve oral hygiene in orthodontic patients in comparison with brushing alone.

2. Mouth wash with $\mathrm{NaF}$ and $\mathrm{CPC}$ can be used as a daily mouth rinse in orthodontic patients to control plaque. While, the mouth wash with $\mathrm{CHX}+\mathrm{CPC}+$ Aloe Vera combination is advisable when the orthodontic patient has gingival inflammation.

3. Repeating oral hygiene instructions is important for the control of oral health condition in orthodontic patient. This can be enhanced by the text messages reminder.

\section{Recommendations}

Further long term studies are recommended to confirm the efficacy of different mouth washes as an anti-plaque and anti-gingivitis agents in orthodontic practice. Moreover, there is a need for new combinations of mouth washes for anti-plaque, with anti-carious and anti-inflammatory actions with least side effects.

\section{Acknowledgement}

The authors wish to Acknowledge College of Dentistry, University of Mosul for the support. Also we wish to acknowledge Dr. Mohamad Nihad form College of Dentistry, University of Mosul for his linguistic assessment and for all of the study participants for their patients and cooperation.

\section{Conflict of interest}

The authors have no conflict of interest.

\section{References}

1. Alogaibi YA, Murshid ZA, Alsulimani FF, Linjawi Al, Almotairi M, Alghamdi M, et al. Prevalence of malocclusion and orthodontic treatment needs among young adults in Jeddah city. J Orthod Sci. 2020 Feb 12;9:3. doi: 10.4103/jos.JOS_44_19. 
2. Jasser RN. The effect of overbite and overjet on clinical parameters of periodontal disease: a case control study. Saudi Dent J. 2020 Feb 19. doi: 10.1016/j.sdentj.2020.02.002

3. Kolawole KA, Folayan MO. Association between malocclusion, caries and oral hygiene in children 6 to 12 years old resident in suburban Nigeria. BMC Oral Health. 2019 Nov 27;19(1):262 doi: 10.1186/s12903-019-0959-2.

4. Teles RP, Teles FR. Antimicrobial agents used in the control of periodontal biofilms: effective adjuncts to mechanical plaque control?. Braz Oral Res. 2009;23 Suppl 1:39-48. doi: 10.1590/s1806-83242009000500007.

5. Beyth N, Redlich M, Harari D, Friedman M, Steinberg D. Effect of sustained-release chlorhexidine varnish on Streptococcus mutans and Actinomyces viscosus in orthodontic patients. Am J Orthod Dentofacial Orthop. 2003 Mar;123(3):345-8. doi: 10.1067/mod.2003.19.

6. Laing E, Ashley P, Gill D, Naini F. An update on oral hygiene products and techniques. Dent Update. 2008 May;35(4):270-9. doi: 10.12968/denu.2008.35.4.270.

7. Sajjan P, Laxminarayan N, Kar PP, Sajjanar M. Chlorhexidine as an antimicrobial agent in dentistry-a review. Oral Health Dent Manag. 2016;15(2):93-100.

8. Tiwari BS, Ankola AV, Sankeshwari RM, Patil P, Kashyap BR, Bolmal UB. Comparison of effectiveness for Stevia rebaudiana and chlorhexidine mouthrinses on plaque and gingival scores among 12-15-year-old government school children in Belagavi City-A randomized controlled trail. Indian J Health Sci Biomed Res (KLEU). 2020 Jan;13(1):32. doi: 10.4103/kleuhsj.kleuhsj_235_18.

9. Akihiro Yoshihara DD, Sakuma PS, Kobayashi PS, Miyazaki PH. Antimicrobial effect of fluoride mouthrinse on mutans streptococci and lactobacilli in saliva. Pediatr Dent. 2001 Mar-Apr;23(2):113-7.

10. Charugundla BR, Anjum S, Mocherla M. Comparative effect of fluoride, essential oil and chlorhexidine mouth rinses on dental plaque and gingivitis in patients with and without dental caries: a randomized controlled trial. Int J Dent Hyg. 2015 May;13(2):104-9. doi: 10.1111/idh.12094.

11. Asadoorian J, Williams KB. Cetylpyridinium chloride mouth rinse on gingivitis and plaque. Am Dent Hyg Assoc. 2008 Oct 1;82(5):42-6.

12. Witt J, Ramji N, Gibb R, Dunavent J, Flood J, Barnes J. Antibacterial and antiplaque effects of a novel, alcohol-free oral rinse with cetylpyridinium chloride. J Contemp Dent Pract. 2005 Feb;6(1):1-9.

13. Ghiraldini B, Furushima ET, Casarin RC, Villalpando KT, Pimentel SP, Cirano FR. Effect of cetylpyridinium chloride with xylitol on the formation of biofilm and development of gingivitis. Braz $J$ Oral Sci. 2012 Sep;11(3):392-5. doi: 10.20396/bjos.v11i3.8641379.

14. Maharani DA, Ramadhani A, Adiatman M, Wimardhani YS, Kusdhany L, Rahardjo A, et al.. Efficacy of mouth rinse formulation based on cetylpyridinium chloride $0.1 \%$ in the control of dental calculus buildup. Int J App Pharm. 2017 Oct;9:176-80. doi: 10.22159/ijap.2017.v9s1.84_91.

15. Ajmera N, Chatterjee A, Goyal V. Aloe vera: It's effect on gingivitis. J Indian Soc Periodontol. 2013 Jul;17(4):435-8. doi: 10.4103/0972-124X.118312.

16. Nair GR, Naidu GS, Jain S, Nagi R, Makkad RS, Jha A. Clinical effectiveness of aloe vera in the management of oral mucosal diseases-a systematic review. Journal of clinical and diagnostic research: J Clin Diagn Res. 2016 Aug;10(8):ZE01-7. doi: 10.7860/JCDR/2016/18142.8222.

17. Vangipuram S, Jha A, Bhashyam M. Comparative efficacy of aloe vera mouthwash and chlorhexidine on periodontal health: A randomized controlled trial. J Clin Exp Dent. 2016 Oct 1;8(4):e442-7. doi: 10.4317/jced.53033.

18. Farid Ayad BD, Prado R, Dentales DE, Mateo LR, Stewart B, BSEng MG, et al. A comparative investigation to evaluate the clinical efficacy of an alcohol-free CPC-containing mouthwash as compared to a control mouthwash in controlling dental plaque and gingivitis: a six-month clinical study on adults in San Jose, Costa Rica. J Clin Dent. 2011;22(6):204-12. 
19. Calvo-Guirado JL, Fernández Domínguez M, Aragoneses JM, Martínez González JM, Fernández-Boderau E, Garcés-Villalá MA, et al. Evaluation of new seawater-based mouth rinse versus chlorhexidine $0.2 \%$ reducing plaque and gingivitis indexes. a randomized controlled pilot study. App Sc. 2020 Jan;10(3):982. doi: 10.3390/app10030982.

20. Zhao H, Xie Y, Meng H. [Effect of fixed appliance on periodontal status of patients with malocclusion] Zhonghua Kou Qiang Yi Xue Za Zhi. 2000 Jul;35(4):286-8. Chinese.

21. Eppright M, Shroff B, Best AM, Barcoma E, Lindauer SJ. Influence of active reminders on oral hygiene compliance in orthodontic patients. Angle Orthod. 2014 Mar;84(2):208-13. doi: 10.2319/062813-481.1.

22. Brent Bowen T, Rinchuse DJ, Zullo T, DeMaria ME. The influence of text messaging on oral hygiene effectiveness. Angle Orthod. 2015 Jul;85(4):543-8. doi: 10.2319/071514-495.1.

23. Iqbal J, Awan R, Parvez MA, ul Haq A, Gardezi AA, Irfan S. Effectiveness of text message instructions on oral hygiene for orthodontic patients. Pakistan Oral Dent J. 2017 Jun 30;37(2):278-82.

24. Scheerman JF, van Meijel B, van Empelen P, Verrips GH, van Loveren C, Twisk JW, et al. The effect of using a mobile application ("WhiteTeeth") on improving oral hygiene: a randomized controlled trial. Int J Dent Hyg. 2020 Feb;18(1):73-83. doi: 10.1111/idh.12415.

25. Pham TA, Nguyen NT, Ngo LT. Comparative effect of chlorhexidine and anti-calculus mouthrinse on dental plaque, gingival inflammation and calculus formation on plaque induced gingivitis patients. BEMS Reports. 2017;3(1):1-5. doi: 10.5530/bems.3.1.1.

26. Heintze SD, Jost-Brinkmann PG, Finke C, Miethke RR.Oral health for the orthodontic patient. Chicago: Quintessence; 1999. p.67-70.

27. Smith RN, Brook AH, Elcock C. The quantification of dental plaque using an image analysis system: reliability and validation. J Clin Periodontol. 2001 Dec;28(12):1158-62. doi: 10.1034/j.1600-051x.2001.281211.x.

28. Al-Anezi SA, Harradine NW. Quantifying plaque during orthodontic treatment: a systematic review. Angle Orthod. 2012 Jul;82(4):748-53. doi: 10.2319/050111-312.1.

29. Ticha R, Bohmova H. Influence of fixed orthodontic appliance on the level of patient's oral hygiene. Orthodoncie. 2005;14(4):29-34.

30. Löe H, Silness J. Periodontal disease in pregnancy I. Prevalence and severity. Acta Odontol Scand. 1963 Dec;21:533-51. doi: 10.3109/00016356309011240.

31. Kumar GS, Kashyap A, Raghav S, Bhardwaj R, Singh A, Guram G. Role of text message reminder on oral hygiene maintenance of orthodontic patients. J Contemp Dent Pract. 2018 Jan 1;19(1):98-101. doi: 10.5005/jp-journals-10024-2219.

32. Li X, Xu ZR, Tang N, Ye C, Zhu XL, Zhou T, Zhao ZH. Effect of intervention using a messaging app on compliance and duration of treatment in orthodontic patients. Clin Oral Invest. 2016 Nov;20(8):1849-1859. doi: 10.1007/s00784-015-1662-6.

33. Wang SY, Yang YH, Chang HP. The effect of an oral hygiene instruction intervention on plaque control by orthodontic patients. J Dent Sci. 2007;2(1):45-51.

34. Pahwa N, Kumar A, Gupta S. Short term clinical effectiveness of a $0.07 \%$ cetylpyridinium chloride mouth rinse in patients undergoing fixed orthodontic appliance treatment. Saudi Dent J. 2011 Jul;23(3):135-41. doi: 10.1016/j.sdentj.2011.03.001.

35. Wiraja VV, Hambali TS, Lambri SE. The comparison of $0.05 \%$ sodium fluoride and $0.2 \%$ chlorhexidine usage and aquadest to the plaque index on fixed orthodontic patients. Padjadjaran J Dent. 2007; 18(1):20-7.

36. Chauhan P, Dua VS, Kainth N, Tosh A, Tomar A. The effect of various oral hygiene products on the microbial flora in patients undergoing orthodontic treatment. APOS Trends Orthod. 2015 Mar;5(2):63-9. doi: 10.4103/2321-1407.152055. 
37. Teng F, He T, Huang S, Bo CP, Li Z, Chang JL, et al. Cetylpyridinium chloride mouth rinses alleviate experimental gingivitis by inhibiting dental plaque maturation. Int J Oral Sci. 2016 Sep 29;8(3):182-90. doi: 10.1038/ijos.2016.18.

38. Al-Maweri SA, Nassani MZ, Alaizari N, Kalakonda B, Al-Shamiri HM, Alhajj MN, et al. Efficacy of aloe vera mouthwash versus chlorhexidine on plaque and gingivitis: a systematic review. Int J Dent Hyg. 2020 Feb;18(1):44-51. doi: 10.1111/idh.12393.

39. Karim B, Bhaskar DJ, Agali C, Gupta D, Gupta RK, Jain A, et al. Effect of Aloe vera Mouthwash on Periodontal Health: Triple Blind Randomized Control Trial. Oral Health Dent Manag. 2014 Mar;13(1):14-9.

40. Dehghani M, Abtahi M, Sadeghian H, Shafaee H, Tanbakuchi B. Combined chlorhexidine-sodiumfluoride mouthrinse for orthodontic patients: clinical and microbiological study. J Clin Exp Dent. 2015 Dec 1;7(5):e569-75. doi: 10.4317/jced.51979.

41. B Aggarwal B, Prasad S, Reuter S, Kannappan R, Yadav VR, Park B, et al. Identification of novel anti-inflammatory agents from Ayurvedic medicine for prevention of chronic diseases: "reverse pharmacology" and "bedside to bench" approach. Curr Drug Targets. 2011 Oct;12(11):1595-653. doi: 10.2174/138945011798109464.

42. Haps S, Slot DE, Berchier CE, Van der Weijden GA. The effect of cetylpyridinium chloride-containing mouth rinses as adjuncts to toothbrushing on plaque and parameters of gingival inflammation: a systematic review. Int J Dent Hyg. 2008 Nov;6(4):290-303. doi: 10.1111/j.1601-5037.2008.00344.x. 